\title{
Peer Advocacy: Expressions of Loyalty in Peer Review
}

\section{Lars Geschwind and Kristina Edström}

\section{Introduction}

Evaluations and assessments are always guided by particular aims and methods, but the evaluators also influence how evaluations are conducted. Evaluators bring to their task different methodological competences and levels of knowledge about the object of evaluation. In addition, the identities, values, beliefs, interests, preferences, personalities, and idiosyncrasies of evaluators may influence their assessments. This is also the case in peer review, the dominant and most legitimate form of evaluation in higher education.

In recent years, the use of peer review has proliferated well beyond the assessment of publications and grant proposals. Policy-makers and university managers also use evaluations based on peer review to inform decision-making, quality assessment, and allocations of funds (Hansen

L. Geschwind $(\bowtie) \bullet K$. Edström

Department of Learning in Engineering Sciences, KTH Royal Institute of Technology, Stockholm, Sweden e-mail: larsges@kth.se 
et al., 2019). Organisations appoint peer reviewers and assign them the task of assessing the preconditions, processes, or outcomes of their peers within a given field (Westerheijden et al., 2007).

Earlier research has shown that academic staff identify to a high degree with and are loyal to their discipline or scientific field (Henkel, 2005). This chapter considers how this sense of loyalty may be reflected in evaluation practices when peer reviewers act as advocates for the peers whom they evaluate (the evaluands). We will use case studies to identify peer advocacy in various forms, whether for the object they are asked to evaluate or for the stakeholders involved. This issue sheds light on and problematizes evaluation practices and evaluation roles, with a particular focus on advocacy in the higher education sector (Morris, 2011).

\section{Aims and Uses of Peer Review}

Evaluations serve different purposes. The main ones are summative, formative, and informative. Summative evaluations are made to control institutions and actors or their activities. High-stakes evaluations can have important consequences for the evaluands and the stakeholders, and some are performed by authorities who control sanctions and resources. Other evaluations are more formative or process-oriented, aiming to support the enhancement of activities. A third common aim is to provide information, often destined to feed into a decision-making process. In higher education and research sectors, the balance between control and enhancement has frequently been discussed in relation to national quality systems (see Ers and Tegler Jerselius' chapter on the Swedish system in this volume). Various national systems have been criticised for placing too much emphasis on control and "sticks" rather than "carrots" (Laughton, 2003), for the unreflective implementation of evaluation machineries (Dahler-Larsen, 2011), and for allowing evaluations to proliferate too much in numerous areas (Hansen et al., 2019). There is also extensive research that focuses on the uses of evaluations, which are related to but not synonymous with their aims. Vedung describes how the intended and unintended uses of evaluations may include not only control and enhancement, but also routines, rituals, and window-dressing, 
with the aim of addressing internal and external stakeholders well beyond the evaluands (Vedung, 2017; see also Karlsson, 2016).

As we have learned from this volume, peer review was first developed as an academic practice. Its roots are found in academic publishing; the practice later spread to other academic decision-making processes such as appointments. It is regarded as a cornerstone of life and culture in academia, and as one of the main ingredients of collegial responsibility in the academic profession (Sahlin \& Eriksson-Zetterquist, 2016). Subjecting one's work to the scrutiny of peers and taking on the task of evaluating the work of others are obligations crucial to academic work.

The legitimacy of peer review is based on the idea that only peers can provide a sufficiently high level of expertise to make judgements in a particular area. At the same time, a certain distance is implied between the peer and what is being evaluated, because someone external and without personal interest in the matter might be less prone to favouritism. External reviewers are also more at liberty to give an honest appraisal, especially when blind (anonymous) review is practised. Hence, there is simultaneously an expectation of necessary affinity, as the reviewers are assumed to have a similarity in competence for understanding the object of evaluation, and of necessary distance, since they are external and disinterested (Merton, 1968).

Peer review as a form of evaluation is intrinsic to academic organisations and academic work. It is routinely used in many decisions and processes in education, research, and in the institutional structures of higher education. However, the boundaries of peer review and the proliferation of peer review as a tool for exercising authority and for management have also been discussed. For instance, peer review panels are increasingly used in areas that were not previously assessed in this way. Their function can differ slightly depending on whether the aim is ranking (candidates in appointment cases), grading (research grant applications, doctoral theses), judging against standards or threshold levels (accreditation of educational programmes, promotion cases), or informing decisions together with formative comments (journal manuscripts, projects), to mention some of the most common aims.

It is well known, and documented in previous research, that peer review does not necessarily produce a non-biased or "neutral" opinion (Lee et al., 2013). Systematic disadvantages for certain groups have been 
identified in peer review, contributing to inequalities in the higher education sector (Wennerås \& Wold, 1997; van den Brink \& Benschop, 2012). No matter how careful the selection of peer reviewers might be, they have ideas and perceptions that may be reinforced or changed during the peer review process. In the case of peer review panels, the inherent group dynamics add complexity (Lamont, 2009). In national systems for evaluating research, there has been much discussion of the methodological question: should the focus be on peer review or on metrics? And if both are used to evaluate research, one may still discuss what should be the relation between these methods (see Butler \& McAllister, 2009). There are instances when reviewers interact with stakeholders during review processes to gather information, often in interviews. In more "democratic" approaches to evaluation, intense stakeholder involvement is a key component (Fagrell et al., 2020).

It is natural that stakeholder representatives seek opportunities to further their own interests and perspectives in the process of evaluation. They frequently come to interviews with a clear agenda, presenting arguments and analyses of their own. It can be hard for the evaluators to sift through wise analyses made with the expertise and insights of the stakeholders, and to identify self-interested appraisals that may be detrimental to other stakeholders. Therefore, it is important for peer reviewers to be able to withstand persuasion and charm from stakeholders who try to engage them as advocates.

\section{Advocacy in Academia}

In this chapter, we seek to shed light on one type of peer reviewer behaviour: namely, when reviewers act as advocates and promoters of the evaluand or any of the stakeholders involved. Our aim is to increase awareness of this phenomenon and to discuss the risks it poses for the legitimacy of peer review. Advocacy in evaluation is not a new topic in evaluation research. Ultimately, it relates to our views on knowledge production and the role played by the evaluator/researcher. Going back to Guba and Lincoln (1989), different generations or, in Vedung's phrase, (2010) "waves" of evaluations and evaluators have embraced different epistemic 
and ontological paradigms. The positivist view of evaluations saw impartial measurement from a distance as the preferred (or only) way to produce valid and reliable knowledge. Other evaluation models have emphasised a more constructivist and relativist view of evaluation practices. Some of these models have implied a closer, even intertwined relationship between the evaluator and the evaluand. Green, for instance, has suggested that advocacy is inevitable, an unavoidable part of evaluation inquiry. She also admits that it has been, and still is, deeply controversial in evaluation communities:

the very notion of evaluation as advocacy invokes shudders of distaste and horror among most members of today's evaluation community, theorists and practitioners alike... Advocacy is the antithesis offair evaluation, according to these founding visions and ideals. To advocate is to espouse and promote a partisan belief or stance, to embrace and advance a cause. To evaluate is, according to tradition, to judge fairly the quality, merit, and worth of a program based on impartial, scientifically gathered information. (Greene, 1997, p. 26)

For Green and others, this is not only a question of scientific standpoint. It is also about power and values: whose interests should evaluation advance? Which values should it represent? Some scholars argue that sympathies with one or several stakeholder groups or preferences, or for or against a particular programme, should not only be brought out in the open and disclosed; they should even be emphasised as part of a democratic and pluralistic agenda (House, 1990). However, serious issues arise when discussing evaluation advocacy, including integrity, fairness, and long-term credibility, and this chapter seeks to address them. Our chief contribution is to discuss advocacy specifically in a peer review context, with the higher education sector as the particular arena. The role of a peer, as mentioned earlier, implies a specific relation to the evaluand, although the notion of peership has changed over time (see Chap. 1 in this volume for a discussion).

Our aim is not to paint peer advocacy as an obvious threat to the integrity of evaluation processes and results. Instead, we approach the phenomena studied here with great curiosity and openness. After all, it is an intrinsic feature of peer review that judgements are made by human 
beings who are capable of empathy for other human beings and their work (Stake, 2004). As some evaluations are formative, with enhancement as their main purpose, there are situations when it is not necessarily problematic for peers to help the evaluand. The question, however, is when and to what extent this kind of help is appropriate, and when there is risk of tilting the balance between stakeholders or compromising the integrity of the evaluation. This makes peer advocacy a potentially sensitive subject. To raise the stakes further, we have chosen to study cases in which we ourselves were involved. Taking Sweden as the empirical arena, we will discuss and exemplify four different experiences of peer advocacy.

\section{Cases of Advocacy}

We will analyse four cases from a Swedish higher education context. We selected the cases as personal experiences where we felt that something was at play that we have come to call peer advocacy. The authors were either involved as evaluators or had insight into the process for other reasons.

- The first case concerns a national review of subjects and programmes. The first author was the panel secretary.

- The second case comes from a Swedish university college that initiated an evaluation of its unit for teaching and learning support. Two evaluators were commissioned and instructed to make separate evaluations; the second author was one of them.

- The third case is a peer review launched by a Swedish university college as part of the application process for becoming a fully-fledged university. The first author was at the time employed at the state agency responsible for evaluating applications for university status.

- The fourth case is an assessment exercise of administrative processes initiated at a Swedish university. Both authors were employed at that university at the time and involved in appointment and promotion processes there.

The materials used are evaluation reports supplemented with reflections from the authors who were involved in the cases. We explored the 
cases "from the inside" both through self-reflection and by interviewing each other. The experiences are lie the past, up to 20 years ago. The temporal distance has the advantage of encouraging honesty, notwithstanding potential embarrassments. In this regard, it helps that the authors have gained many new experiences since these particular cases; they have also grown older. The disadvantage is that their memory of details of the cases and their contemporary contexts may have faded somewhat.

In the following, the cases are described without the distraction of too many details. All quotes are translated from Swedish; some are lightly edited for brevity.

\section{Case 1: National Reviews of Subjects and Programmes}

The first case is taken from national evaluations of educational programmes and subjects leading to general degrees. The aim was to check that subjects and programmes were of sufficient quality, with the possible sanction of a warning that the degree-awarding rights of that particular higher education institution might be revoked if it fell short of standards. The chosen evaluation model focused on institutional preconditions, processes, and results (Franke, 2002). Panels consisted of academic staff from Swedish and other Nordic institutions and representatives of students and doctoral students, aided by a secretary from the national agency. The evaluation model was based on self-evaluations by the institutions, and site visits by the external peer review panel. During the period studied here, the national assessments in Sweden resulted in 30 reports. A final report by the agency included, as a separate part, the peer review panel report (Stensaker, 2000).

We have gone through the summaries and conclusions in each report. What we found particularly interesting in relation to the topic discussed here are the frequent remarks about working conditions for teachers. This theme was present in 24 of the 30 reports. The panels comment especially on heavy faculty workloads, the limited scope for research and development, the pressure to apply for external funding, and insecure conditions of employment. These topics were also mentioned in a conference paper written by the secretary at the agency: 
What we have seen in the national assessments is first of all that many teachers do an excellent job. They work hard, they are enthusiastic, and they want what is best for their students. Many think they have the best job there is. The drawbacks are long working hours, insecure employments, especially for junior academics, and limited scope for research and development. In the past decade, salaries and societal status seem to have decreased as well. (Geschwind, 2004, p. 12)

That the panels brought up such themes in the evaluations is unsurprising, as the preconditions for education were indeed included in the evaluation criteria. What is striking is the balance and proportions. The overall impression of the evaluations is that much less attention was paid to results and to education processes such as teaching methods and assessment than to the difficulties faced by teachers themselves.

This case shows that the national evaluations of education in this system included a fair amount of peer advocacy. By focusing on the preconditions for education, and more specifically on working conditions for academic staff, most evaluation reports discussed topics such as workload, time available for research, and even the Swedish funding system. Although the evaluand as such was the quality of educational programmes, colleagues from the Nordic countries and the secretary at the agency instead seemed inclined to assist their colleagues by acting as advocates who drew attention to difficult working conditions on behalf of their peers, and recommending improvements.

Perhaps as a consequence of this, the architects of the next national evaluation model faced a good deal of political pressure to focus on results only, resulting in a period of conflict in the higher education sector between the Ministry of Education and the agency (see Ers and Tegler Jerselius in this volume).

\section{Case 2: Institutional Review of an Academic Development Unit}

The next example is an evaluation of the academic development unit of a higher education institution. The unit's main purpose was to provide courses in teaching and learning in higher education for academic staff. 
At the time, professors and associate professors were required to have ten weeks of such education. This requirement was mandated in the Higher Education Ordinance together with a set of nationally agreed learning objectives (Lindberg-Sand \& Sonesson, 2008). The Pro-Rector who had supported the establishment of the unit commissioned the evaluation shortly before her retirement. It is likely that the evaluation was made a part of the handover in order to protect the unit from reorganisation, as this type of unit was often reorganised when managers were replaced (Gosling, 2008; Challis et al., 2009; Palmer et al., 2010).

Two evaluators, both active at similar units in Swedish universities, were instructed to work separately without communicating. They were given the same documents and made separate site visits, interviewing mainly the same stakeholder representatives, including the unit's staff, university leadership at all levels, faculty, and students. The brief asked for a thorough analysis and documentation of the unit in the light of comparable national and international work, together with recommendations for its future development.

When the evaluations were presented to the institution in an open seminar, it became clear that they were very different. One evaluator's report was twelve pages long, presenting an analysis and recommendations supported by brief descriptions. The perspective emphasised was that of faculty members who were participants in courses given by the unit. About half the report was devoted to complaints from faculty members about the courses being compulsory:

The problem lies in what is described as "studentification" of the teachers who participate in the courses. This is seen as mistrust in the ability of staff to take responsibility for their own pedagogical development. They also see it as an expression of low respect, or lack of trust in the participating teachers' ability to define their own needs for further pedagogical education. For instance, they mention how the courses are assessed, requiring them to cite course literature. The focus is on course participants being able to demonstrate knowledge, or to mention the regulations that steer education. The critique is that the same patterns are followed that course participants use on their students. This is seen as very problematic, not least by teachers who hold PhDs. 
Most of the recommendations made at the end of the report aimed to oblige those who criticised the unit's courses, for instance suggesting that the unit should switch to a softer approach, a "carrot" model.

The other evaluator devoted 54 pages to explaining academic development in a national and international perspective, analysing the needs and conditions at this institution in particular, and evaluating the work of the unit in some detail. The overall judgement was positive, and recommendations aimed at organisational stability and increased resources. Here, the main perspective was to further academic development at the institution, but also more widely. That the courses were required was taken as a given, as this was regulated at the national level. The critique from a small minority of faculty was depicted from the viewpoint of the academic developers leading the courses. What appeared is a mirror image of the preceding quote:

The pedagogical courses do not take place in a social vacuum. This activity has various identities - it is the long arm of the university leadership while also being academic or emancipatory, and this often creates dissonance... Assessment is a particularly sensitive matter, since it puts to the test both the format for assessment and the legitimacy of those who make the assessment. That the courses are de facto compulsory pushes every such issue to its limits, and course leaders encounter various forms of resistance... This friction must be seen in the light of its complex political and social context —only then can workable strategies be found. The course leaders must be able to navigate these troubled waters, through a well-developed understanding of their role.

This evaluator was explicitly situated the academic development unit in a context of several diverse interests, positioning faculty members as just one voice in a stakeholder chorus:

The task of the pedagogical courses is to enable and drive the development of the educational programmes by supporting staff development. Pedagogical competence must be interpreted more widely than just the individual teacher's desires and needs; it must be seen in relation to the aims and challenges of the educational programs and the institution. 
Despite the different approaches reflected in these two evaluations, both were essentially positive and made strikingly similar recommendations regarding increased resources to the unit. But while both evaluators brought up other interests in their analyses, they clearly held one particular perspective in the foreground. If one evaluator took a stance defending the views of academic staff, the other can be seen as a peer advocate for academic development endeavours. These positions were likely influenced by their own backgrounds. One evaluator was a full professor whose part-time engagement in academic development was tied to a particular research area. The other was invested in academic development, also on national and international levels. We note that it was only the way that the evaluation was designed, with two separate and parallel evaluations instead of a single collaborative one, that revealed these different perspectives. If the evaluators had worked together, they would likely have conciliated their interests and presented a unified result.

\section{Case 3: External Evaluators Appointed to Promote an Application for University Status}

The third case is that of a university college preparing an application for full university status. The government had rejected a previous application; in fact, it was not even sent out for review. This time, as part of the preparations, the rector commissioned an evaluation that was conducted by an external peer review panel of distinguished professors. The composition of the group is worth mentioning in some detail. One panel member had previously been a driving force for establishing the university college as a new seat of learning. Another member was then Rector at an institution that had just been granted university status. Other prominent professors from major Swedish universities made up the rest of the review panel. A manager from the university college acted as secretary.

In the report, the panel declared that their experiences were important:

The Board of the University College decided to update the application for university status. In parallel with this update, the Rector of the University College has hired us to make a situation assessment based on our experience of university business and of assessment work. 
The evaluation used the same criteria that had previously been applied for university status. The first part of the report is based on key figures that compare the university college with the last three Swedish institutions that had been "promoted" to university status. The comparison showed that the university college was on par with, or even above, the level of these three universities. To assess educational standards, a metaevaluation of the National Agency for Higher Education's reports was utilised. In their conclusion, the panel praised the university college and strongly recommended that it should be elevated to university status:

At the University College there is accumulated capital in the form of high ambition, good work morale, high-class infrastructure, and not least a corps of academic staff with high academic competence who can be expected to work well under the conditions that a university status confers.

This case shows us how a peer review panel can be commissioned and composed, and the evaluation set up, for a specific purpose-in this case to support an application for university status. The positive outcome of the evaluation was only as expected. Nevertheless, the government resisted, and did not award university status. Instead, it communicated that this avenue was closed, and a period of mergers followed (Benner \& Geschwind, 2016).

\section{Case 4: HR Competencies in Academic Appointment Processes}

The last case comes from a university that initiated a comprehensive internal evaluation of its administrative processes. The evaluation followed the logic of previous exercises in research (RAE) and education (EAE) assessment, and it was named the Administrative Assessment Exercise (AAE). The evaluation design was also similar to these other exercises, comprising a self-evaluation written by the evaluands and a panel of external experts who analysed the written material, undertook a site visit on campus, and delivered a report.

While the overall aim of the exercise was to improve the quality of administration, two other interesting aims were also identified: 
The AAE was also expected to have a number of positive side effects. Amongst these was to increase the administrative staff's knowledge about evaluations and quality work, including a greater understanding of the processes that teachers and researchers continuously undergo in exercises such as RAE and EAE. Through the $A A E$, administrative work would also become more visible throughout the organisation. This development, in turn, would facilitate better communication between administration, faculty, students, and other stakeholders.

It was thus seen as important for professional support staff to learn more about evaluations as phenomena that have profound effects on academic life. But a further purpose of the AAE was to give administrative work more recognition within the organisation.

Unlike many other evaluations, including previous education and research assessment exercises at this university, the AAE focused on processes rather than organisational units. One of these processes was the appointment of faculty, described as "a strategic process that requires intense administration-academy interaction.” A senior administrative officer chaired the panel, which also comprised experienced human resources officers, with the exception of a professor emerita. The panel report includes a number of interesting passages. Under the heading "Competence," the tension between the academics and HR officers is discussed. Unclear roles and a blurred division of labour had created, overall though not everywhere, a situation of mutual distrust. It seems that this lack of trust was rooted in traditional practice:

There is a strong tradition that has great legitimacy in academia to appoint academic staff after peer review, without the involvement of $H R$, which would be unthinkable in many other organisations. However, there is a trend in many universities to ask for and appreciate HR competence.

One of the suggested ways to better utilise HR competence is to focus more on the candidates' personal abilities and leadership issues. According to the panel, other assessment criteria than the current ones would also bring HR into the process of selecting candidates for academic positions, a task that was perceived at the time as being largely in the hands of external peer reviewers. 
Further arguments were put forward about the importance of HR competences:

Also from a cost perspective, HR competence is important in the recruitment process. It contributes not only to finding the right person for a position, but also to avoiding appointing the wrong person. A failed recruitment carries enormous costs. A trained and experienced interviewer might more easily identify possible risk personalities and investigate concerns more closely providing a better basis for decisions about employment.

Finally, in the concluding section two out of three panel recommendations for the future revolve around the roles and contributions of HR personnel. The first is to "strengthen awareness of and confidence in what different roles contribute" and the second is simply to "increase HR competence in the process."

\section{Discussion}

All these cases involve evaluations in higher education, and some show how peer review is used in new academic processes. We chose them not because they are representative of all or most cases of peer review, but we wanted to illustrate a phenomenon so common that we have seen several instances in our own experiences. In every case, we can see that the evaluators demonstrate strong loyalty towards their peers. They recognise and show understanding of their colleagues' situation and needs. It is beyond the scope of this chapter to discuss advocacy in relation to results, outcomes, or effects, but other studies have shown that peer reviewers can focus on difficult working conditions as way to explain and sometimes excuse poor performances (see Geschwind, 2016). Furthermore, it becomes clear that one is a peer in a context. The nature of the commission and particular evaluation models, methods, interactions, and expectations can present different opportunities for the peer role. A particular situation may offer more or less opportunity for peer advocacy, and the instinct to further the interests of one's peers may be aroused to various degrees. 
Case 1 shows that while the evaluation model at the time encompassed working conditions, processes, and results, the peer role seemed to shift the balance significantly towards the former. Although the aim was to evaluate the quality of programmes, the peer reviewers also cast a strong light on other factors beyond the evaluands. In practice, the panels delivered what amounts to a wish list related to funding systems and institutional governance. The reviewers seemed to be torn between their commission to evaluate quality and their loyalty towards frustrated peers. One way to limit opportunities for peer advocacy, then, might be to use more structured evaluation models that leave reviewers less room to comment on matters that lie beyond the review's main focus. The composition of a panel may also help to keep a balance, since the presence of other stakeholders might hold in check the instinct to promote the perspective of one's peers in a one-sided way. In this case, however, the presence of other stakeholder representatives - who in all likelihood had a different set of interests and loyalties-was not sufficient to balance the academic peers of discontented faculty, who were in the majority.

Case 2 shows that it is not always obvious who the peer reviewer is a peer to, when there are several stakeholders. Here we saw conflicting peer advocacies over the same evaluand. Hence, the peer role varies with reviewers' relations to stakeholders. While a peer review panel is often composed to ensure that different stakeholder interests are represented, a sole evaluator has more room to engage in peer advocacy. In this case, the different perspectives became apparent only because there were two evaluators working separately. Had the two evaluators been asked to collaborate, they would probably have weighed various interests against each other in their deliberations and presented a unified result. Had there been just one evaluator, the result could have gone either way. But in the absence of a comparison, the peer advocacy might have gone unnoticed. Since a proliferation of biased evaluations would undermine the legitimacy of peer review, on balance the model based on separate evaluations has advantages.

Case 3 is an example of how an evaluation might be initiated with a specific aim and intended use. It seems clear that the desired result was implicit from the outset, as the evaluation was to be used for a specific 
purpose: namely, to strengthen the application for full university status. The evaluation was obviously aimed at mobilising a group of friendly supporters; it was wilfully rigged with peer advocacy as the sole purpose. We note, however, that the university college's application was unsuccessful. Perhaps the quality of the application made little difference in a situation where they lacked the necessary political support, and not even this group of illustrious peers could help their cause. The institution's efforts of self-promotion may also have been too conspicuous. They did succeed, however, in establishing an image of the institution as on a par with some universities. In future attempts to gain university status, they can always pull up this report from the archives and use it again. This case also raises the question of where evaluators should draw the line to preserve their own integrity and legitimacy.

Case 4 has shown how peer advocacy can also work to further the interests of university managers. In most university settings, appointment processes are based on the classic form of peer review, where colleagues from the same academic field are trusted to assess candidates' merits. In this case, the panel, consisting of HR officers and other senior administrators, stressed the need for greater clarity regarding division of labour between management and academics, and called for increased mutual respect. But they also took the opportunity provided by the evaluation process to propose fundamental changes in appointment processes. They advanced the idea that HR competences could be more extensively utilised, even if this meant changing certain criteria for appointing academic staff. It is not clear to us, however, whether these HR advocates fully understand the academic context. We wonder if the perspective of their own type of expertise makes them see some essential and even valuable characteristics of academia as flaws that ought to be corrected.

\section{Conclusions and Recommendations}

Peer review is the most legitimate way to judge quality in higher education, and often the only feasible one. It involves the judgements of experts who are also ordinary humans with a capacity for empathy towards the people involved. However, too much bias carries the risk of watering 
down legitimacy, thereby corrupting peer review as an institution. It is not merely the results of any specific evaluation that are at stake, but also the role of peer review as a cornerstone of academic life, culture, and autonomy. This suggests that anyone involved in peer review processes has a great responsibility to preserve the integrity of this form of evaluation.

Peer advocacy should not only be understood as emanating from peer reviewers themselves. As we have shown, it can also be enabled or limited by the way in which a review is commissioned, the specific evaluation model, the criteria and conditions that the commissioning client sets out, and by both real and perceived expectations. We recommend, firstly, that the client who commissions an evaluation should strive to be transparent and clear about their chosen evaluation model, methods, and criteria. Secondly, clients may want to take into account the interests of stakeholders when appointing peer reviewers. For an evaluation to be credible, thirdly, the evaluators must have the chance to undertake an actual investigation, and base the results on materials that they collect and document; the result should never be given a priori. Finally, peer reviewers too should bear all these issues in mind. There may be situations when it is appropriate to turn down an invitation, to protest during a skewed process, and to deliver results that were not what the client desired.

\section{References}

Benner, M., \& Geschwind, L. (2016). Conflicting rationalities: Mergers and consolidations in Swedish higher education policy. In R. Pinheiro, L. Geschwind, \& T. Aarrevaara (Eds.), Mergers in Higher Education. The Experience from Northern Europe (pp. 43-58). Springer.

Butler, L., \& McAllister, I. (2009). Metrics or peer review? Evaluating the 2001 UK research assessment exercise in political science. Political Studies Review, 7(1), 3-17.

Challis, D., Holt, D., \& Palmer, S. (2009). Teaching and learning centres: towards maturation. Higher Education Research \& Development, 28(4), 371-383.

Dahler-Larsen, P. (2011). The Evaluation Society. Stanford University Press.

Fagrell, P., Gunnarsson, S., \& Fahlgren, A. (2020). Curriculum development and quality assurance of higher education in Sweden: The external stakeholder perspective. Journal of Praxis in Higher Education, 2(1), 28-45. 
Franke. (2002). From Audit to Assessment: A national perspective on an international issue. Quality in Higher Education, 8(1), 23-28.

Geschwind, L., (2004). Working Conditions for University Teachers in Sweden: Findings from the assessments of subjects and programs 2001-2003, paper presented at the 26th EAIR forum, Barcelona, 5-8 September 2004.

Geschwind, L. (2016). Academic core values and quality: the case of teachingresearch links. In M. Elmgren, M. Folke-Fichtelius, S. Hallsén, H. Román, \& W. Wermke (Eds.), Att ta utbildningens komplexitet på allvar: En vänskrift till Eva Forsberg (pp. 227-238). Acta Universitatis Upsaliensis.

Gosling, D. (2008). Educational Development in the UK, Report to the Heads of Education Development Group (HEDG), February 2008.

Greene, J. C. (1997). Evaluation as advocacy. Evaluation practice, 18(1), 25-35. Guba, E. G., \& Lincoln, Y. S. (1989). Fourth generation evaluation. Newbury Park, Calif.: Sage.

Hansen, H. F., Aarrevaara, T., Geschwind, L., \& Stensaker, B. (2019). Evaluation practices and impact: Overload? In R. Pinheiro, L. Geschwind, H. F. Hansen, \& K. Pulkkinen (Eds.), Reforms, organizational change and performance in higher education: A comparative account from the Nordic countries. Palgrave Macmillan.

Henkel, M. (2005). Academic identity and autonomy in a changing policy environment. Higher Education, 49(1-2), 155-176.

House, E. R. (1990). Methodology and justice. New Directions for Program Evaluation, 1990(45), 23-36.

Karlsson, S. (2016). The active university: Studies of contemporary Swedish higher education. (Doctoral dissertation, KTH Royal Institute of Technology).

Lamont, M. (2009). How professors think. Harvard University Press.

Laughton, D. (2003). Why was the QAA approach to teaching quality assessment rejected by academics in UK HE? Assessment \& Evaluation in Higher Education, 28(3), 309-321.

Lee, C. J., Sugimoto, C. R., Zhang, G., \& Cronin, B. (2013). Bias in peer review. Journal of the American Society for Information Science and Technology, 64(1), 2-17.

Lindberg-Sand, Å., \& Sonesson, A. (2008). Compulsory Higher Education Teacher Training in Sweden: Development of a national standards framework based on the Scholarship of Teaching and Learning. Tertiary Education and Management, 14(2), 123-139.

Merton, R. K. (1968). Social Theory and Social Structure, enlarged version. The Free Press. 
Morris, M. (2011). The good, the bad, and the evaluator: 25 years of AJE ethics. American Journal of Evaluation, 32(1), 134-151.

Palmer, S., Holt, D., \& Challis, D. (2010). Australian teaching and learning centres through the eyes of their directors: characteristics, capacities and constraints. Journal of Higher Education Policy and Management, 32(2), 159-172.

Sahlin, K., \& Eriksson-Zetterquist, U. (2016). Collegiality in modern universities-the composition of governance ideals and practices. Nordic Journal of Studies in Educational Policy, 2016(2-3), 33640.

Stake, B. (2004). How far dare an evaluator go toward saving the world? American Journal of Evaluation, 25(1), 103-107.

Stensaker, B. (2000). Quality as Discourse: An Analysis of External Audit Reports in Sweden 1995-1998. Tertiary Education and Management, 6(4), 305-317.

Van den Brink, M., \& Benschop, Y. (2012). Gender practices in the construction of academic excellence: Sheep with five legs. Organization, 19(4), 507-524.

Vedung, E. (2010). Four waves of evaluation diffusion. Evaluation, 16(3), 263-277.

Vedung, E. (2017). Public policy and program evaluation. Routledge.

Wennerås, C., \& Wold, A. (1997). Sexism and nepotism in peer-review. Nature, 387(6631), 341-343.

Westerheijden, D. F., Stensaker, B., \& Rosa, M. J. (Eds.). (2007). Quality assurance in higher education: Trends in regulation, translation and transformation (Vol. 20). Springer Science \& Business Media. 
Open Access This chapter is licensed under the terms of the Creative Commons Attribution 4.0 International License (http://creativecommons.org/licenses/ by/4.0/), which permits use, sharing, adaptation, distribution and reproduction in any medium or format, as long as you give appropriate credit to the original author(s) and the source, provide a link to the Creative Commons licence and indicate if changes were made.

The images or other third party material in this chapter are included in the chapter's Creative Commons licence, unless indicated otherwise in a credit line to the material. If material is not included in the chapter's Creative Commons licence and your intended use is not permitted by statutory regulation or exceeds the permitted use, you will need to obtain permission directly from the copyright holder.

(c) (i) 